\title{
Efficacy and Safety of Once Weekly Dulaglutide in East Asian Patients with Type 2 Diabetes: Subgroup Analysis by Potential Influential Factors
}

\author{
Jianhua Ma $\cdot$ Bin Zhang $\cdot$ Jianing Hou $\cdot$ Yongde Peng
}

Received: August 11, 2020 / Accepted: October 21, 2020 / Published online: November 8, 2020

(C) The Author(s) 2020

\begin{abstract}
Introduction: This subgroup analysis assessed the efficacy and safety of once weekly dulaglutide $1.5 \mathrm{mg}$ and $0.75 \mathrm{mg}$ in East Asian patients with type 2 diabetes (T2D) stratified by key demographic and baseline characteristics.

Methods: Change from baseline in glycated hemoglobin $(\mathrm{HbA} 1 \mathrm{c})$, fasting blood glucose (FBG) and body weight were analyzed by age ( $<60$ years, $\geq 60$ years), gender (male, female), body weight $(<70 \mathrm{~kg}, \geq 70 \mathrm{~kg})$, BMI $(<25 \mathrm{~kg} /$ $\left.\mathrm{m}^{2}, \geq 25 \mathrm{~kg} / \mathrm{m}^{2}\right)$, duration of diabetes ( $<10$ years, $\geq 10$ years), baseline HbA1c $(<8.5 \%, \geq 8.5 \%)$ and concomitant oral antihyperglycemic medications (OAMs; metformin
\end{abstract}

Electronic supplementary material The online version of this article (https://doi.org/10.1007/s13300020-00955-2) contains supplementary material, which is available to authorized users.

J. Ma

Department of Endocrinology, Nanjing First

Hospital, Nanjing, China

B. Zhang · J. Hou ( $\square)$

Lilly China Drug Development and Medical Affairs

Center, Shanghai, China

e-mail: hou_jia_ning@lilly.com

Y. Peng $(\bowtie)$

Department of Endocrinology and Metabolism,

Shanghai First People's Hospital, Shanghai Jiao Tong

University, Shanghai, China

e-mail: pengyongde0908@126.com only, SU only, metformin + SU) at week 26 and 52 in East Asian patients from the AWARDCHN2 study. Incidence of gastrointestinal adverse events (GI AEs) and hypoglycemia was evaluated.

Results: A total of 422 East Asian patients with T2D were included in this subgroup analysis. At week 26, the reduction of HbA1c and FBG from baseline were similar across subgroups, except that patients with baseline HbA1c $\geq 8.5 \%$ had greater HbA1c and FBG reductions than patients with baseline HbA1c $<8.5 \%$. Gender analysis showed HbA1c difference that was not clinically significant. The decrease in body weight varied across different subgroups in both dulaglutide doses; however, the difference was not clinically significant. The incidence of GI AEs and total hypoglycemia was generally similar across subgroups in both doses. A similar trend was observed at week 52 in both dulaglutide doses.

Conclusions: In East Asian patients with T2D, treatment with dulaglutide $(1.5 \mathrm{mg}$ and $0.75 \mathrm{mg}$ ) demonstrated significant improvements in glycemic control irrespective of all subgroups, except baseline HbA1c, with greater HbA1c and FBG reductions in patients with higher baseline HbA1c. Dulaglutide was well tolerated with a similar safety profile to other GLP-1 receptor agonists.

Trial Registration: ClinicalTrials.gov Identifier: NCT01648582. 
Keywords: Dulaglutide; East Asian patients; Type 2 diabetes

\section{Key Summary Points}

\section{Why carry out this study?}

Dulaglutide, a once-weekly glucagon-like peptide-1 (GLP-1) receptor agonist (RA), is a proven treatment option as an adjunct to diet and exercise to improve glycemic control in adults with type 2 diabetes (T2D)

The AWARD-CHN2 study showed that dulaglutide demonstrated improvement in glycated hemoglobin (HbA1c) and was associated with weight loss and lower risk of hypoglycemia compared with glargine in mainly Asian patients with T2D who had failed to achieve optimal glycemic control on metformin and/or a SU

The effects of dulaglutide on East Asian patients with different demographic profiles and baseline characteristics including gender, duration of diabetes and baseline HbA1c, etc., have not yet been reported. To further get a clear understanding of any potential influential factors impacting efficacy and safety profiles, we conducted this subgroup analysis

This analysis evaluated the potential influential factors on glycemic control with dulaglutide at week 26 and week 52, in East Asian (China and South Korea) patients from AWARD-CHN2 study

\section{What was learned from the study?}

Results show that at week 26 , there was improvement in glycemic control with both dulaglutide doses $(1.5 \mathrm{mg}$ and $0.75 \mathrm{mg}$ ) regardless of age, gender, weight, BMI, duration of diabetes, or concomitant OAMs in East Asian patients with T2D who failed to achieve optimal glycemic control with OAMs
With both doses of dulaglutide, greater HbA1c and FBG reductions were observed in patients with higher baseline HbA1c

Overall, the effect of dulaglutide treatment on change in body weight, incidence of GI AEs and hypoglycemic risk was generally not influenced by different subgroup factors

Similar results were observed at week 52

\section{DIGITAL FEATURES}

This article is published with digital features, including a summary slide, to facilitate understanding of the article. To view digital features for this article go to https://doi.org/10.6084/ m9.figshare.13089323.

\section{INTRODUCTION}

Over the last few decades, there has been an epidemic rise in the number of people with diabetes, especially type 2 diabetes (T2D) [1]. The International Diabetes Federation estimates that by 2045 close to 693 million people will be affected by diabetes [1]. The rise is particularly alarming in developing countries, since $>80 \%$ of cases occur in these countries [2]. Estimates show that around $60 \%$ of the people with diabetes live in Asia, with maximum prevalence in East Asia [2].

Glucagon-like peptide-1 (GLP-1) receptor agonist (RA) is a recommended treatment option as an adjunctive therapy or monotherapy in patients with T2D who have inadequate glycemic control on oral antihyperglycemic medications (OAMs) [3-5]. In mainly Asian patients with T2D, the AWARD-CHN2 study demonstrated that dulaglutide is efficacious and well tolerated [6]. The AWARD CHN2 study compared the efficacy and safety of once-weekly dulaglutide with that of once-daily insulin glargine in combination with metformin and/or a sulphonylurea (SU) in mainly Asian patients with T2D. Results showed that dulaglutide 
demonstrated improvement in glycated hemoglobin (HbA1c) and was associated with weight loss and lower risk of hypoglycemia compared with glargine in mainly Asian patients with T2D who had failed to achieve optimal glycemic control on metformin and/or a SU [6]. However, the effects of dulaglutide in East Asian patients with different demographic profiles and baseline characteristics including gender, duration of diabetes and baseline HbA1c, etc., have not yet been reported. Regarding this and to further get a clear understanding of any potential influential factors impacting efficacy and safety profiles, we conducted this subgroup analysis. The analysis evaluated the potential influential factors affecting glycemic control with dulaglutide at week 26 and week 52 in East Asian (China and South Korea) patients from AWARD-CHN2 study.

\section{METHODS}

\section{Study Design and Treatment}

AWARD-CHN2 was a 52-week, randomized, parallel-arm, open-label (blinded to dulaglutide dose), active comparator controlled, phase 3 study. The study was conducted at 45 sites in China, Russia, Mexico and South Korea. The detailed method and study design have been previously reported. The primary outcome was change in HbA1c from baseline to week 26 to determine non-inferiority of dulaglutide $1.5 \mathrm{mg}$ versus glargine [6]. The current analyses evaluated the efficacy and safety data of once weekly dulaglutide $1.5 \mathrm{mg}$ and $0.75 \mathrm{mg}$ after 26 weeks and 52 weeks of treatment, stratified by baseline characteristics in East Asian (China and South Korea) patients with T2D.

\section{Patients}

Key inclusion criteria were patients aged $\geq 18$ years with a diagnosis of T2D for at least 6 months, a body mass index (BMI) $\geq 19.0$ and $\leq 35.0 \mathrm{~kg} / \mathrm{m}^{2}$ and HbA1c between 7 and $11 \%$ at screening; patients had been taking metformin and/or a SU for at least 3 months and were on a stable therapeutic dose (at least half the maximum dose according to the product information in the country of treatment) for at least 8 weeks before screening [6]. Institutional ethics committee approval was obtained, and written informed consent was taken from each patient before participation. The study was conducted in consensus with the Declaration of Helsinki, Good Clinical Practice and applicable laws and regulations [7]. A full list of the Institutional Review Boards that approved this study can be found in the Supplementary Material.

\section{Study Assessments and Statistical Analysis}

The following efficacy endpoints were analyzed at week 26 and week 52 , in dulaglutide $(1.5 \mathrm{mg}$ and $0.75 \mathrm{mg}$ ) treated patients across different demographic subgroups: changes in HbA1c, reductions in fasting blood glucose (FBG) and change in body weight. Safety analyses included the incidence of gastrointestinal adverse events (GI AEs) and incidence and 1-year rate of hypoglycemia.

The subgroups were stratified according to key potential influential factors: age ( $<60$ years, $\geq 60$ years), gender, body weight $(<70 \mathrm{~kg}, \geq 70 \mathrm{~kg})$, BMI $\left(<25 \mathrm{~kg} / \mathrm{m}^{2}, \geq 25 \mathrm{~kg} /\right.$ $\left.\mathrm{m}^{2}\right)$, duration of diabetes $(<10$ years, $\geq 10$ years), baseline HbA1c $(<8.5 \%, \geq 8.5 \%)$ and concomitant OAMs (metformin only, SU only, metformin $+\mathrm{SU}$ ).

Efficacy analyses of change from baseline were conducted using analysis of covariance (ANCOVA), with treatment, subgroup, treatment by subgroup interaction as fixed effects and baseline value as covariate, with two exceptions: baseline HbA1c was not included as a covariate in the analyses of change in HbA1c or FBG for the baseline HbA1c subgroup, and baseline weight was not included as a covariate in the analysis of change in weight for baseline weight subgroup. Least-square (LS) mean, 95\% confidence intervals (CIs) and $p$ values for the comparisons between the subgroups were computed from the ANCOVA model. Missing values were imputed using last observation carried forward (LOCF). GI AEs were reported as 
percentages, calculated based on the number of patients in each subgroup category.

\section{RESULTS}

\section{Patient Disposition and Baseline Characteristics}

A total of 422 (DU $1.5 \mathrm{mg}: 213$ and DU $0.75 \mathrm{mg}$ : 209) East Asian patients with T2D were included in this subgroup analysis. The patient demographics and characteristics are presented in Table 1 . Overall, around $60 \%$ of patients were male in both the dulaglutide dose groups. Mean duration of diabetes was $8.1 \pm 5.0$ years and $8.0 \pm 5.3$ years, mean $\mathrm{HbA} 1 \mathrm{c}$ was $8.4 \pm 1.2 \%$ and $8.3 \pm 1.1 \%$, mean body weight was $71.9 \pm 12.0 \mathrm{~kg}$ and $73.3 \pm 12.2 \mathrm{~kg}$, and mean

Table 1 Demographic and baseline characteristics

\begin{tabular}{lll}
\hline & $\begin{array}{l}\text { DU 1.5 mg } \\
(\boldsymbol{N}=\mathbf{2 1 3})\end{array}$ & $\begin{array}{l}\text { DU 0.75 mg } \\
(\boldsymbol{N}=\mathbf{2 0 9})\end{array}$ \\
\hline Age, mean (SD), years & $54.7(10.0)$ & $53.9(10.2)$ \\
Gender, $n$ (\%) & $125(58.7)$ & $126(60.3)$ \\
Male & $88(41.3)$ & $83(39.7)$ \\
Female & $71.9(12.0)$ & $73.3(12.2)$ \\
Body weight, mean (SD), kg & $25.8(3.2)$ & $26.3(3.4)$ \\
BMI, mean (SD), kg/m ${ }^{2}$ & $8.1(5.0)$ & $8.0(5.3)$ \\
$\begin{array}{l}\text { Duration of T2D, mean } \\
\quad \text { SD), years }\end{array}$ & $8.4(1.2)$ & $8.3(1.1)$ \\
HbAlc, mean (SD), \% & $9.9(2.7)$ & $9.6(2.3)$ \\
FBG, mean (SD), mmol/1 & & \\
Concomitant OAMs ${ }^{\mathrm{a}}$, & & \\
$n$ (\%) & & \\
Metformin only & $91(42.7)$ & $88(42.3)$ \\
Sulfonylurea only & $28(13.1)$ & $27(13.0)$ \\
Metformin + sulfonylurea & $94(44.1)$ & $93(44.7)$ \\
\hline
\end{tabular}

$B M I$ body mass index, $D U$ dulaglutide, $F B G$ fasting blood glucose, $H b A 1 c$ glycated hemoglobin, $O A M$ oral antihyperglycemic medication, $S D$ standard deviation

${ }^{a} n=208$ in DU $0.75 \mathrm{mg}$ group
BMI was $25.8 \pm 3.2 \mathrm{~kg} / \mathrm{m}^{2}$ and $26.3 \pm 3.4 \mathrm{~kg} /$ $\mathrm{m}^{2}$ in dulaglutide $1.5 \mathrm{mg}$ and $0.75 \mathrm{mg}$, respectively.

\section{Changes from Baseline in HbA1c}

Figure 1 presents the change from baseline in HbA1c at week 26 stratified by subgroups. At week 26, the reduction in HbA1c from baseline was similar across age, weight, BMI, duration of diabetes and concomitant OAMs, with no significant differences between the subgroups in both dulaglutide $1.5 \mathrm{mg}$ and dulaglutide $0.75 \mathrm{mg}$. Significant differences were observed in the reduction of $\mathrm{HbA} 1 \mathrm{c}$ from baseline between baseline HbA1c at both dulaglutide doses, in line with observations from previous dulaglutide trials $[8,9]$. The LS mean \pm standard error (SE) change from baseline in HbA1c reduction was greater in patients with higher baseline HbA1c compared to patients with lower baseline HbA1c in dulaglutide $1.5 \mathrm{mg}$ (HbA1c $\geq 8.5 \%: \quad-\quad 2.38 \pm 0.12 \%, \quad$ HbA1c $<8.5 \%$ : $\quad-1.28 \pm 0.11 \% ; \quad p<0.05) \quad$ and dulaglutide $\quad 0.75 \mathrm{mg} \quad$ (HbA1c $\geq 8.5 \%$ : $-1.76 \pm 0.13 \%$, HbA1c < 8.5\%: $-1.04 \pm 0.11 \%$; $p<0.05)$. Gender analysis showed that there was a significant difference in HbA1c reduction in both dulaglutide groups. Male patients had greater HbA1c reduction compared with female patients in dulaglutide $1.5 \mathrm{mg}$ (LS mean change, male: $-1.82 \pm 0.11 \%$, female: $-1.55 \pm 0.12 \%$; $p<0.05$ ) and dulaglutide $0.75 \mathrm{mg}$ (LS mean change, male: $\quad 1.48 \pm 0.11$, female: $-1.22 \pm 0.12 \% ; p<0.05)$.

A similar finding was observed at week 52 for both dulaglutide doses (Supplementary Table 1). A significant difference was observed in the reduction of $\mathrm{HbA} 1 \mathrm{c}$ from baseline between baseline HbA1c and gender. HbA1c reduction was greater in patients with higher baseline HbA1c compared to patients with lower baseline $\mathrm{HbA1c}$ in dulaglutide $1.5 \mathrm{mg}$ (LS mean \pm SE change, HbA1c $\geq 8.5 \%:-2.18 \pm$ $0.13 \%$, HbA1c < 8.5\%: $\quad-\quad 1.11 \pm 0.12 \%$; $p<0.05)$ and dulaglutide $0.75 \mathrm{mg} \quad$ (LS \pm mean \pm SE change, HbA1c $\geq 8.5 \%$ : $-1.50 \pm$ $0.14 \%, \quad$ HbA1c $<8.5 \%: \quad-\quad 0.90 \pm 0.12 \%$; $p<0.05)$. Similarly, in male patients the 


\begin{tabular}{|c|c|c|c|c|c|c|c|c|c|}
\hline \multirow[b]{2}{*}{ Factor } & \multirow[b]{2}{*}{ Subgroup } & \multicolumn{4}{|c|}{ DU $1.5 \mathrm{mg}$} & \multicolumn{3}{|c|}{ DU $0.75 \mathrm{mg}$} & \\
\hline & & $\mathrm{n}$ & $\begin{array}{l}\text { LS mean } \\
\text { from ba }\end{array}$ & $\begin{array}{l}\text { change } \\
\text { eline }\end{array}$ & & n & $\begin{array}{l}\text { LS mean change } \\
\text { from baseline }\end{array}$ & & \\
\hline \multirow{2}{*}{ Age } & $<60$ years & 149 & -1.70 & $\longmapsto$ & & 150 & -1.37 & $\longmapsto$ & ' \\
\hline & 260 years & 64 & -1.67 & $\longmapsto$ & & $1 \quad 59$ & -1.35 & $\longmapsto$ & 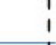 \\
\hline \multirow{2}{*}{ Gender } & Male & 125 & -1.82 & $\longmapsto$ & & 126 & -1.48 & $\longmapsto$ & * \\
\hline & Female & 88 & -1.55 & $\longmapsto$ & 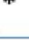 & $\begin{array}{l}183 \\
\end{array}$ & -1.22 & $\longmapsto 1$ & ] \\
\hline \multirow{2}{*}{ Weight } & $<70 \mathrm{~kg}$ & 94 & -1.69 & $\longmapsto-1$ & & 92 & -1.39 & $\longmapsto$ & i \\
\hline & $270 \mathrm{~kg}$ & 119 & -1.70 & $\longmapsto$ & & $\begin{array}{ll}117 \\
117\end{array}$ & -1.35 & $\longmapsto$ & i \\
\hline \multirow{2}{*}{ BMI } & $<25 \mathrm{~kg} / \mathrm{m}^{2}$ & 92 & -1.77 & $\longmapsto$ & & 86 & -1.47 & $\longmapsto$ & 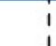 \\
\hline & $\geq 25 \mathrm{~kg} / \mathrm{m}^{2}$ & 121 & -1.64 & $\longmapsto$ & & 123 & -1.29 & $\longmapsto$ & 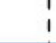 \\
\hline \multirow{2}{*}{$\begin{array}{l}\text { Duration } \\
\text { of diabetes }\end{array}$} & $<10$ years & 146 & -1.73 & $\mapsto-1$ & & 142 & -1.45 & $\longmapsto$ & 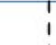 \\
\hline & $\geq 10$ years & 67 & -1.64 & $\longmapsto$ & & 67 & -1.22 & $\longmapsto$ & i \\
\hline \multirow{2}{*}{$\begin{array}{l}\text { Baseline } \\
\text { HbA1c }\end{array}$} & $<8.5 \%$ & 125 & -1.28 & $\longmapsto$ & & 124 & -1.04 & $\longmapsto$ & 71 \\
\hline & $\geq 8.5 \%$ & 88 & -2.38 & $\longmapsto$ & & $\begin{array}{l}85 \\
18\end{array}$ & -1.76 & $\longmapsto$ & ] \\
\hline \multirow{3}{*}{$\begin{array}{l}\text { Concomitant } \\
\text { OAMs }\end{array}$} & Metformin only & 91 & -1.68 & $\longmapsto$ & & 88 & -1.32 & $\longmapsto$ & 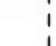 \\
\hline & su only & 28 & -1.71 & $\longmapsto$ & & 27 & -1.58 & $\longmapsto$ & 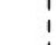 \\
\hline & Metformin + su & 94 & -1.63 & $\longmapsto$ & & 93 & -1.28 & $\longmapsto$ & 1 \\
\hline \multirow{2}{*}{\multicolumn{2}{|c|}{$\begin{array}{l}\text { Overall East Asian } \\
\text { population }\end{array}$}} & 213 & -1.69 & $\mapsto$ & & 209 & -1.37 & $\mapsto$ & I \\
\hline & & & Г & $\begin{array}{c} \\
-1.5\end{array}$ & & $\begin{array}{l}7 \\
0\end{array}$ & $\begin{array}{r}\Gamma \\
-3\end{array}$ & $\begin{array}{c}1 \\
-1.5\end{array}$ & 7 \\
\hline
\end{tabular}

Fig. 1 Changes in HbAlc after 26 weeks stratified by potential influential factors. ${ }^{*} p<0.05$. LS mean, 95\% CI and $p$ values were calculated from the ANCOVA model. $A N C O V A$ analysis of covariance, $B M I$ body mass index, $C I$

reduction in HbA1c was greater compared to female patients in dulaglutide $1.5 \mathrm{mg}$ (LS mean change \pm SE, male: $-1.65 \pm 0.12 \%$, female: $-1.35 \pm 0.13 ; p<0.05)$. The rest of the subgroups showed no significant differences in reduction of HbA1c from baseline to week 52 .

\section{Reduction in Fasting Blood Glucose Levels}

FBG reductions from baseline were similar across age, gender, weight, baseline BMI, duration of diabetes and concomitant OAMs, with no significant difference among the subgroups in dulaglutide $1.5 \mathrm{mg}$ and $0.75 \mathrm{mg}$ at week 26 (Fig. 2). Patients with higher baseline HbA1c values had greater reductions compared to patients with lower baseline values in dulaglutide $1.5 \mathrm{mg}$ (LS mean $\pm \mathrm{SE}, \mathrm{HbA} 1 \mathrm{c} \geq 8.5 \%$ : $-2.91 \pm 0.32 \mathrm{mmol} / \mathrm{l}, \mathrm{HbA} 1 \mathrm{c}<8.5 \%:-1.65 \pm$ $0.30 \mathrm{mmol} / \mathrm{l} ; p<0.05)$ and dulaglutide $0.75 \mathrm{mg}$ (LS mean $\pm \mathrm{SE}, \quad \mathrm{HbA1c} \geq 8.5 \%$ : $\quad-2.17 \pm$ $0.33 \mathrm{mmol} / \mathrm{l}, \quad$ HbA1c $<8.5 \%$ : $\quad-\quad 1.25 \pm$ confidence interval, $D U$ dulaglutide, HbAlc glycated hemoglobin A1c, $L S$ least square, $O A M$ oral antihyperglycemic medication, $S U$ sulfonylurea

$0.30 \mathrm{mmol} / \mathrm{l} ; p<0.05)$. A similar trend was also observed at week 52 (Supplementary Table 2).

\section{Changes from Baseline in Body Weight}

At week 26, the decrease in body weight varied across different subgroups in dulaglutide $1.5 \mathrm{mg}$ and dulaglutide $0.75 \mathrm{mg}$ treatment; however, the differences were not considered to be clinically significant (Fig. 3). In dulaglutide $1.5 \mathrm{mg}$, there were differences (LS mean \pm SE) in change from baseline in body weight between subgroup categories of duration of diabetes $(<10$ years: $-0.97 \pm 0.34 \mathrm{~kg}, \geq 10$ years: $-1.85 \pm 0.40 \mathrm{~kg}$; $p<0.05)$ and baseline HbA1c $(<8.5 \%$ : $-1.85 \pm 0.35 \mathrm{~kg}, \geq 8.5 \%$ : $\quad-0.63 \pm 0.37 \mathrm{~kg}$; $p<0.05)$. A similar trend was also observed at week 52 (Supplementary Table 3). 


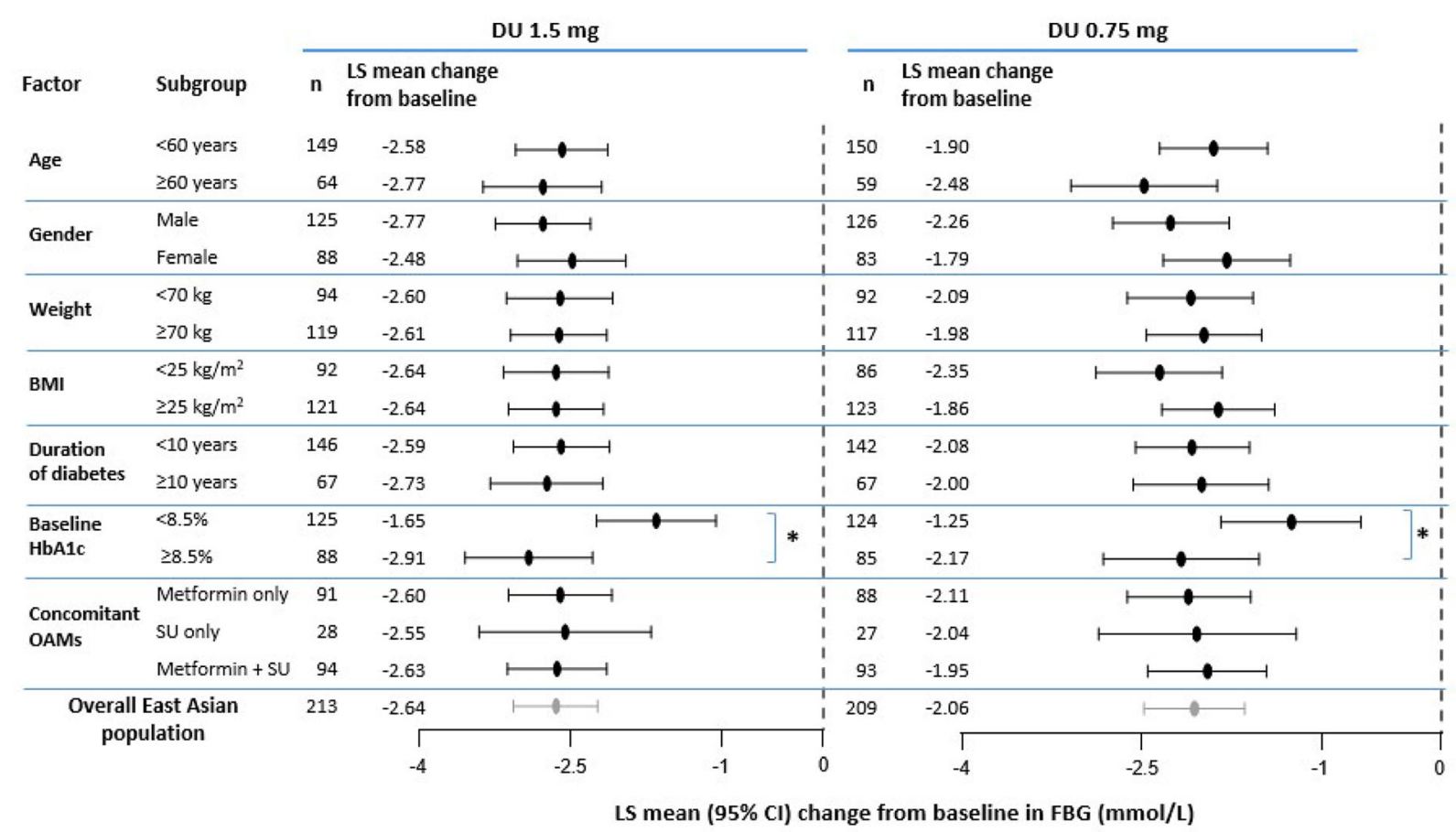

Fig. 2 Changes in fasting blood glucose after 26 weeks stratified by potential influential factors. ${ }^{*} p<0.05$. LS mean, 95\% CI and $p$ values were calculated from the ANCOVA model. ANCOVA analysis of covariance, $C I$

\section{Gastrointestinal Adverse Events and Incidence of Hypoglycemia}

At week 26, percentages of patients reporting GI AEs were generally similar across different subgroup categories (Table 2). Similarly, the incidence and 1 year rate of total hypoglycemia were consistent across all subgroup categories for both dulaglutide doses except for baseline HbA1c and concomitant OAM usage (Table 3). In patients with baseline $\mathrm{HbA} 1 \mathrm{c}<8.5 \%$, the incidence of hypoglycemia was higher compared to patients with baseline HbA1c $\geq 8.5 \%$ in dulaglutide $1.5 \mathrm{mg}$ (HbA1c < 8.5\%: 22.5\%, HbA1c $\geq 8.5 \%: 8.0 \%$ ) and dulaglutide $0.75 \mathrm{mg}$ (HbA1c < 8.5\%: 19.2\%, HbA1c $\geq 8.5 \%: 9.0 \%$ ). For concomitant OAM use, more patients on dulaglutide $1.5 \mathrm{mg}$ treatment in combination with metformin + SU experienced hypoglycemic episodes (26.6\%) compared with patients taking only metformin $(9.7 \%)$ or only SU (6.7\%). In dulaglutide $0.75 \mathrm{mg}$, patients confidence interval, $D U$ dulaglutide, $F B G$ fasting blood glucose, $L S$ least square, $O A M$ oral antihyperglycemic medication, $S U$ sulfonylurea

taking metformin + SU (21.5\%) and only SU (32.1\%) experienced more hypoglycemic episodes compared with patients taking only metformin $(3.3 \%)$.

\section{DISCUSSION}

This post hoc analysis of the AWARD CHN 2 study of once-weekly dulaglutide $1.5 \mathrm{mg}$ and $0.75 \mathrm{mg}$ evaluated the efficacy and safety data after 26 weeks and 52 weeks of treatment stratified by age, gender, body weight, BMI, duration of diabetes, baseline HbA1c and use of concomitant OAMs. This is the first analysis of dulaglutide $1.5 \mathrm{mg}$ and $0.75 \mathrm{mg}$ stratified across demographic subgroups in an East Asian (China and South Korea) population.

Dulaglutide $(1.5 \mathrm{mg}$ and $0.75 \mathrm{mg})$ treatment resulted in a significant reduction in HbA1c from baseline to week 26 and week 52 regardless of age, weight, BMI, duration of diabetes and 


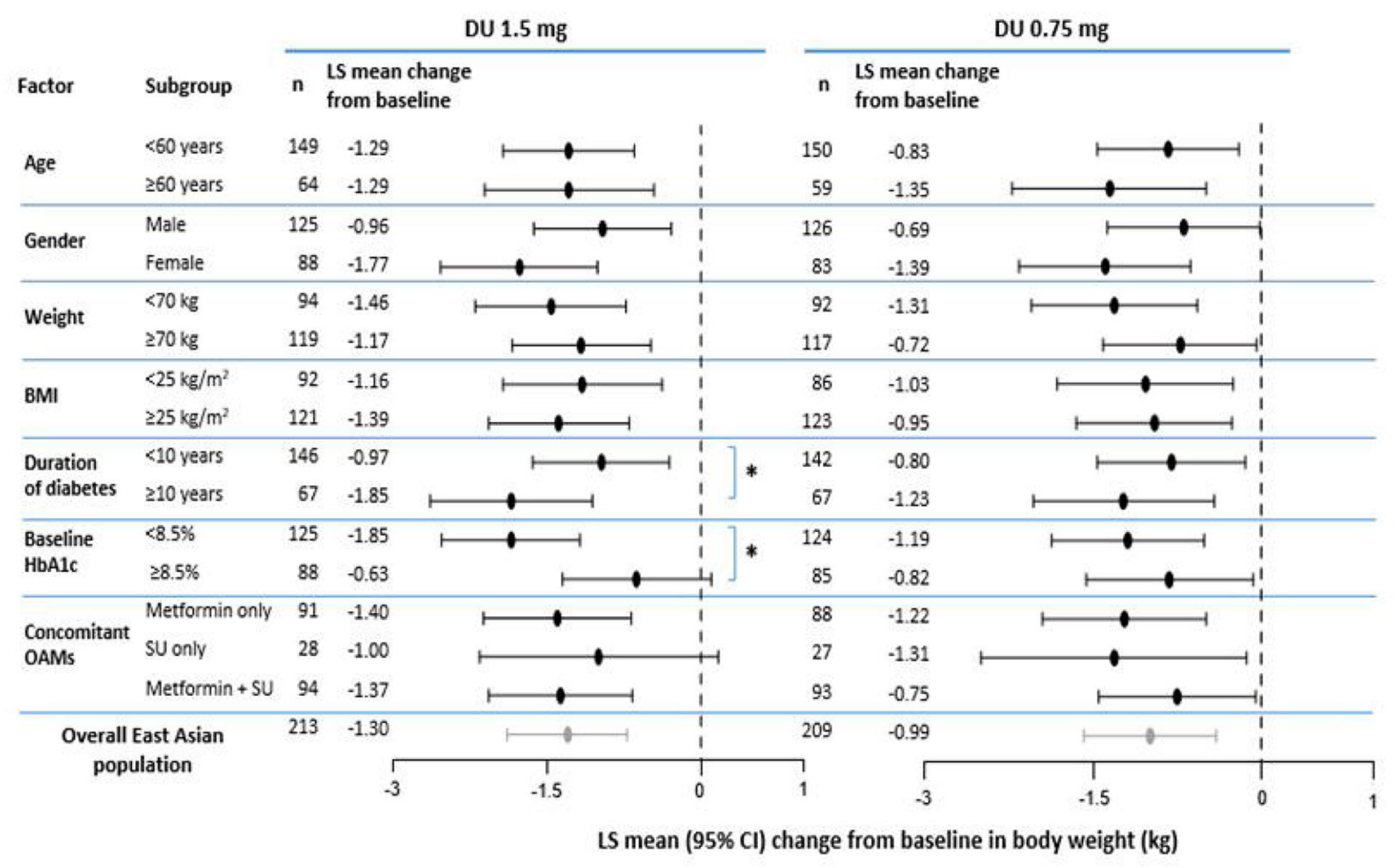

Fig. 3 Change in body weight after 26 weeks by potential influential factors. ${ }^{*} p<0.05$. LS mean, 95\% CI and $p$ values were calculated from the ANCOVA model. $A N C O V A$ analysis of covariance, $B M I$ body mass index, $C I$

use of concomitant OAMs for both dulaglutide doses. Similarly, significant improvement was observed in $\mathrm{HbA1c}$ reductions from baseline (LS mean \pm SE) in the overall East Asian population treated with dulaglutide $1.5 \mathrm{mg}(-1.69 \pm$ $0.09 \%)$ and dulaglutide $0.75 \mathrm{mg}(-1.37 \pm$ $0.09 \%)$. The most influential factor for reduction in HbA1c was HbA1c at baseline. The HbA1c reduction was greater in patients with higher HbA1c at baseline in both dulaglutide doses. A similar observation was reported in previous studies with dulaglutide $1.5 \mathrm{mg}$ and $0.75 \mathrm{mg}$ in a global patient population [8] and dulaglutide $0.75 \mathrm{mg}$ in a Japanese patient population [9]. These studies reported that poorly controlled HbA1c at baseline had a greater HbA1c reduction with dulaglutide compared to patients with lower baseline HbA1c $[8,9]$. This was also reported in two studies with other GLP1 RAs, in which treatment with liraglutide [10] and lixisenatide [11] showed a greater reduction confidence interval, $D U$ dulaglutide, $L S$ least square, $O A M$ oral antihyperglycemic medication, $S U$ sulfonylurea

in HbA1c in patients with higher baseline HbA1c. Furthermore, we observed that at week 26 , in male patients treated with dulaglutide $1.5 \mathrm{mg}$ and $0.75 \mathrm{mg}$, the $\mathrm{HbA} 1 \mathrm{c}$ reduction was greater compared with that of female patients. This finding shows some differences compared to previous studies of dulaglutide in the global population and in Japanese patients $[8,9]$ or with other GLP-1 RAs (exenatide twice daily [12], exenatide once weekly [13] and lixisenatide [11]), which reported no differences between gender in reduction of HbA1c. However, the difference between genders observed in this analysis was not considered clinically significant, and at week 52 the difference was observed only in the dulaglutide $1.5 \mathrm{mg}$ group. Also, in the dulaglutide $1.5 \mathrm{mg}$ group, male patients had a higher baseline HbA1c compared to female patients, which could be a potential reason for significant differences between genders for dulaglutide $1.5 \mathrm{mg}$. 
Table 2 Incidence of GI AEs through 26 weeks by potential influential factors

\begin{tabular}{|c|c|c|c|c|}
\hline \multirow[t]{2}{*}{ Subgroup } & \multicolumn{2}{|c|}{ DU $1.5 \mathrm{mg}$} & \multicolumn{2}{|c|}{ DU $0.75 \mathrm{mg}$} \\
\hline & $n$ & $\geq 1$ GI TEAE, $n(\%)$ & $n$ & $\geq 1$ GI TEAE, $n(\%)$ \\
\hline \multicolumn{5}{|l|}{ Age } \\
\hline$<60$ years & 152 & $46(30.3)$ & 152 & $38(25.0)$ \\
\hline$\geq 60$ years & 65 & $23(35.4)$ & 62 & $18(29.0)$ \\
\hline \multicolumn{5}{|l|}{ Gender } \\
\hline Male & 129 & $32(24.8)$ & 127 & $32(25.2)$ \\
\hline Female & 88 & $37(42.0)$ & 87 & $24(27.6)$ \\
\hline \multicolumn{5}{|l|}{ Weight } \\
\hline$<70 \mathrm{~kg}$ & 94 & $34(36.2)$ & 94 & $23(24.5)$ \\
\hline$\geq 70 \mathrm{~kg}$ & 123 & $35(28.5)$ & 120 & $33(27.5)$ \\
\hline \multicolumn{5}{|l|}{ BMI } \\
\hline$<25 \mathrm{~kg} / \mathrm{m}^{2}$ & 93 & $27(29.0)$ & 88 & $21(23.9)$ \\
\hline$\geq 25 \mathrm{~kg} / \mathrm{m}^{2}$ & 124 & $42(33.9)$ & 126 & $35(27.8)$ \\
\hline \multicolumn{5}{|l|}{ Duration of diabetes } \\
\hline$<10$ years & 150 & $41(27.3)$ & 145 & $31(21.4)$ \\
\hline$\geq 10$ years & 67 & $28(41.8)$ & 69 & $25(36.2)$ \\
\hline \multicolumn{5}{|l|}{ Baseline HbAlc } \\
\hline$<8.5 \%$ & 129 & $45(34.9)$ & 125 & $31(24.8)$ \\
\hline$\geq 8.5 \%$ & 88 & $24(27.3)$ & 89 & $25(28.1)$ \\
\hline \multicolumn{5}{|l|}{ Concomitant OAMs } \\
\hline Metformin only & 93 & $29(31.2)$ & 92 & $23(25.0)$ \\
\hline Sulfonylurea only & 30 & $12(40.0)$ & 28 & $4(14.3)$ \\
\hline Metformin + sulfonylurea & 94 & $28(29.8)$ & 93 & $28(30.1)$ \\
\hline
\end{tabular}

Percentages are calculated based on the number of patients in each subgroup category

$A E$ adverse event, $B M I$ body mass index, $D U$ dulaglutide, GI gastrointestinal, HbAlc glycated hemoglobin, $O A M$ oral antihyperglycemic medication

In the East Asian population, dulaglutide treatment demonstrated meaningful reductions in HbA1c that did not differ by different durations of diabetes subgroups. This finding is consistent with a global population treated with dulaglutide [8] and patients treated with other GLP-1 RAs (exenatide twice daily [12], exenatide once weekly [13], liraglutide [14], albiglutide [15] or lixisenatide [11]). These findings suggest that in patients with relatively long duration of diabetes, GLP-1 RAs could be an effective treatment option. However, previously it was reported that in patients treated with liraglutide uncontrolled on insulins, the glucose-lowering effect depends on the duration of diabetes and beta-cell function [16, 17]. In our study, the glucose-lowering effect did not vary based on duration of diabetes, which could be due to 
Table 3 Incidence and 1-year rate of hypoglycemia through 26 weeks by potential influential factors

\begin{tabular}{|c|c|c|c|c|c|c|}
\hline \multirow{2}{*}{$\begin{array}{l}\text { Factor } \\
\text { Subgroup }\end{array}$} & \multicolumn{3}{|c|}{ DU $1.5 \mathrm{mg}$} & \multicolumn{3}{|c|}{ DU $0.75 \mathrm{mg}$} \\
\hline & $n$ & Incidence, $n$ (\%) & Rate, mean & $n$ & Incidence, $n$ (\%) & Rate, mean \\
\hline \multicolumn{7}{|l|}{ Age } \\
\hline$<60$ years & 152 & $21(13.8)$ & 0.55 & 152 & $19(12.5)$ & 0.87 \\
\hline$\geq 60$ years & 65 & $15(23.1)$ & 1.88 & 62 & $13(21.0)$ & 1.13 \\
\hline \multicolumn{7}{|l|}{ Gender } \\
\hline Male & 129 & $20(15.5)$ & 0.83 & 127 & $23(18.1)$ & 1.28 \\
\hline Female & 88 & $16(18.2)$ & 1.12 & 87 & $9(10.3)$ & 0.47 \\
\hline \multicolumn{7}{|l|}{ Weight } \\
\hline$<70 \mathrm{~kg}$ & 94 & $18(19.1)$ & 1.09 & 94 & $15(16.0)$ & 1.33 \\
\hline$\geq 70 \mathrm{~kg}$ & 123 & $18(14.6)$ & 0.84 & 120 & $17(14.2)$ & 0.65 \\
\hline \multicolumn{7}{|l|}{ BMI } \\
\hline$<25 \mathrm{~kg} / \mathrm{m}^{2}$ & 93 & $15(16.1)$ & 0.62 & 88 & $16(18.2)$ & 1.64 \\
\hline$\geq 25 \mathrm{~kg} / \mathrm{m}^{2}$ & 124 & $21(16.9)$ & 1.19 & 126 & $16(12.7)$ & 0.46 \\
\hline \multicolumn{7}{|l|}{ Duration of diabetes } \\
\hline$<10$ years & 150 & $20(13.3)$ & 0.69 & 145 & $22(15.2)$ & 1.07 \\
\hline$\geq 10$ years & 67 & $16(23.9)$ & 1.51 & 69 & $10(14.5)$ & 0.70 \\
\hline \multicolumn{7}{|l|}{ Baseline HbAlc } \\
\hline$<8.5 \%$ & 129 & $29(22.5)$ & 1.19 & 125 & $24(19.2)$ & 0.92 \\
\hline$\geq 8.5 \%$ & 88 & $7(8.0)$ & 0.59 & 89 & $8(9.0)$ & 0.99 \\
\hline \multicolumn{7}{|l|}{ Concomitant OAMs } \\
\hline Metformin only & 93 & $9(9.7)$ & 0.60 & 92 & $3(3.3)$ & 0.09 \\
\hline Sulfonylurea only & 30 & $2(6.7)$ & 0.27 & 28 & $9(32.1)$ & 1.58 \\
\hline Metformin + sulfonylurea & 94 & $25(26.6)$ & 1.50 & 93 & $20(21.5)$ & 1.62 \\
\hline
\end{tabular}

Total hypoglycemic episodes are presented; rate $=$ events $/$ patient $/$ year

$B M I$ body mass index, $D U$ dulaglutide, $H b A 1 c$ glycated hemoglobin, $O A M$ oral antihyperglycemic medication

differences in study design and patient population. Further analysis is warranted to explore the relationship between the glucose-lowering effect and duration of diabetes and beta-cell function.

We also analyzed the reduction in FBG with dulaglutide $1.5 \mathrm{mg}$ and $0.75 \mathrm{mg}$. In the overall East Asian population, there were significant FBG reductions from baseline (LS mean \pm SE) in the dulaglutide $1.5 \mathrm{mg}(-2.64 \pm 0.21 \mathrm{mmol} / \mathrm{l})$ and dulaglutide $0.75 \mathrm{mg}(-2.06 \pm 0.21 \mathrm{mmol} /$ l) groups. The FBG reductions were consistent with the HbA1c reduction at both dulaglutide doses irrespective of all the subgroup categories. This result was consistent with a previous post hoc analysis of dulaglutide in a global patient population [8].

In this analysis, the decrease in body weight from baseline varied across the subgroups for dulaglutide $1.5 \mathrm{mg}$ and $0.75 \mathrm{mg}$, but the 
differences were not considered to be clinically significant. We observed a significant decrease (LS mean \pm SE) from baseline in body weight in the East Asian population treated with dulaglutide $1.5 \mathrm{mg}(-1.30 \pm 0.30 \mathrm{~kg})$ and $0.75 \mathrm{mg}(-0.99 \pm 0.30 \mathrm{~kg})$. Notably, with both doses of dulaglutide, reduction in body weight was not significantly different according to baseline BMI. Similarly, reduction in body weight did not differ between the baseline body weight subgroup categories for the dulaglutide $1.5 \mathrm{mg}$ group. In the dulaglutide $0.75 \mathrm{mg}$ group though, there were some differences between the baseline body weight subgroups; however, this difference was small and not considered clinically significant. These observations show that weight loss with dulaglutide treatment is not influenced by baseline BMI or baseline body weight. Similar findings are reported with other GLP-1 RAs, including exenatide twice daily [12], exenatide once weekly [13], lixisenatide [11] and liraglutide [18].

Overall, the incidence of GI AEs and hypoglycemia with dulaglutide treatment was similar with no striking differences among the subgroups. In the dulaglutide $1.5 \mathrm{mg}$ group, female patients experienced more GI AEs, which is consistent with previous studies with dulaglutide in global and Japanese patient populations $[8,9]$. In these studies, dulaglutide-treated women experienced higher incidences of nausea and vomiting. This was also observed with other GLP-1 RAs (once weekly exenatide and liraglutide) [13]. The incidence and 1-year rate of total hypoglycemia with both the dulaglutide doses were generally higher in patients with baseline HbA1c of $<8.5 \%$, which was similar to that observed in the global patient population treated with dulaglutide [8]. Also, older patients experienced more hypoglycemic episodes compared to younger patients, which is consistent with observations in a dulaglutide-treated Japanese patient population [9] and with lixisenatide [19]. This could be because generally in older patients with T2D aged $>60$ years, hypoglycemia is a frequently observed adverse event [20]. Furthermore, we observed a higher incidence of hypoglycemia in patients taking concomitant SU either as monotherapy or in combination with metformin. As reported previously, concomitant use of SU with GLP-1 $\mathrm{RA}$ is a risk factor for hypoglycemia. The benefit of GLP-1 RA is that it does not cause hypoglycemia when combined with metformin or thiazolidinediones, but the dose of concomitant SU or insulin may have to be decreased to reduce the risk of hypoglycemic episodes [21]. Of note, we observed that all findings at week 26 were consistent and similar at week 52 , suggesting long-term benefits with both the dulaglutide doses in East Asian patients with T2D irrespective of subgroup factors.

This analysis had several limitations. As this was a subgroup analysis of a previously conducted trial, the statistical power is for the primary analysis results and not specific to this subgroup analysis; there is an imbalance in sample size due to the smaller number of patients in each subgroup, and the results are from a single trial, hence the need to interpret them with caution. Patients enrolled in the clinical trial were controlled by study-specific inclusion and exclusion criteria as this was an RCT; hence, the results may vary from the realworld T2D population in clinical practice.

\section{CONCLUSION}

In conclusion, the present analysis reported that there was improvement in glycemic control with both dulaglutide doses $(1.5 \mathrm{mg}$ and $0.75 \mathrm{mg}$ ) regardless of the age, gender, weight, BMI, duration of diabetes or concomitant OAMs in East Asian patients with T2D who failed to achieve optimal glycemic control with OAMs. With both doses of dulaglutide, greater HbA1c and FBG reductions were observed in patients with higher baseline HbA1c. Overall, the effect of dulaglutide treatment on change in body weight, incidence of GI AEs and hypoglycemic risk was generally not influenced by different subgroup factors.

\section{ACKNOWLEDGEMENTS}

Funding. This study and the journal's Rapid Service Fee were funded and supported by Eli Lilly and Company. 
Medical Writing and Editorial Assistance. The authors thank Dr. Rakesh Ojha, $\mathrm{PhD}$, and Deepika Kajarekar from Syneos Health for medical writing support. The authors also thank Junjun Liu and Junyan Chen from Eli Lilly and Company for preparing the first draft and the final revision, review and critical suggestions for improvement. Medical writing assistance was funded by Eli Lilly and Company.

Authorship. All named authors meet the International Committee of Medical Journal Editors (ICMJE) criteria for authorship for this article, take responsibility for the integrity of the work as a whole, and have given their approval for this version to be published.

Authorship Contributions. All authors: (1) made substantial contributions to the conception or design of the work or the acquisition, analysis or interpretation of data for the work AND (2) drafted the work or revised it critically for important intellectual content AND (3) gave final approval of the version to be published AND (4) agreed to be accountable for all aspects of the work in ensuring that questions related to the accuracy or integrity of any part of the work are appropriately investigated and resolved.

Prior Presentation. The contents from this manuscript were previously presented as a poster at "The 23rd Scientific Meeting of the Chinese Diabetes Society; Xiamen, Fujan, China; Nov 20-23, 2019."

Disclosures. Bin Zhang and Jianing Hou are employees of Eli Lilly and Company. Jianhua Ma and Yongde Peng have nothing to disclose.

Compliance with Ethics Guidelines. Institutional ethics committee approval was obtained for both studies, and written informed consent was taken from each patient before participation. Both studies were conducted in accordance with the Declaration of Helsinki, Good Clinical Practice and applicable laws and regulations (World Medical Association Declaration of Helsinki, 1997). A full list of the Institutional Review Boards that approved this study can be found in the Supplementary Material.

Data Availability. The datasets generated during and/or analyzed during the current study are available from the corresponding author on reasonable request.

Open Access. This article is licensed under a Creative Commons Attribution-NonCommercial 4.0 International License, which permits any non-commercial use, sharing, adaptation, distribution and reproduction in any medium or format, as long as you give appropriate credit to the original author(s) and the source, provide a link to the Creative Commons licence, and indicate if changes were made. The images or other third party material in this article are included in the article's Creative Commons licence, unless indicated otherwise in a credit line to the material. If material is not included in the article's Creative Commons licence and your intended use is not permitted by statutory regulation or exceeds the permitted use, you will need to obtain permission directly from the copyright holder. To view a copy of this licence, visit http://creativecommons.org/licenses/by$\mathrm{nc} / 4.0 /$.

\section{REFERENCES}

1. Cho NH, Shaw JE, Karuranga S, et al. IDF diabetes atlas: global estimates of diabetes prevalence for 2017 and projections for 2045. Diabetes Res Clin Pract. 2018;138:271-81.

2. Ramachandran A, Snehalatha C, Shetty AS, Nanditha A. Trends in prevalence of diabetes in Asian countries. World J Diabetes. 2012;3:110-7.

3. American Diabetes Association. Pharmacologic approaches to glycemic treatment: standards of medical care in diabetes-2020. Diabetes Care. 2020;43(Suppl 1):S98-110. https://doi.org/10.2337/ dc20-S009.

4. Jia W, Weng J, Zhu D, et al. Standards of medical care for type 2 diabetes in China 2019. Diabetes Metab Res Rev. 2019;35:e3158. 
5. Kim MK, Ko SH, Kim BY, et al. Clinical practice guidelines for type 2 diabetes mellitus in Korea. Diabetes Metab J. 2019;43:398-406.

6. Wang W, Nevárez L, Filippova E, et al. Efficacy and safety of once-weekly dulaglutide versus insulin glargine in mainly Asian patients with type 2 diabetes mellitus on metformin and/or a sulphonylurea: a 52-week open-label, randomized phase III trial. Diabetes Obes Metab. 2019;21:234-43.

7. World Medical Association declaration of Helsinki. Recommendations guiding physicians in biomedical research involving human subjects. JAMA. 1997;277:925-6.

8. Gallwitz B, Dagogo-Jack S, Thieu V, et al. Effect of once-weekly dulaglutide on glycated haemoglobin (HbA1c) and fasting blood glucose in patient subpopulations by gender, duration of diabetes and baseline HbA1c. Diabetes Obes Metab. 2018;20: 409-18.

9. Onishi Y, Oura T, Nishiyama H, et al. Subgroup analysis of phase 3 studies of dulaglutide in Japanese patients with type 2 diabetes. Endocr J. 2016;63:263-73.

10. Henry RR, Buse JB, Sesti G, et al. Efficacy of antihyperglycemic therapies and the influence of baseline hemoglobin $\mathrm{A}(1 \mathrm{C})$ : a meta-analysis of the liraglutide development program. Endocr Pract. 2011;17:906-13.

11. Blonde L, Chava P, Dex T, et al. Predictors of outcomes in patients with type 2 diabetes in the lixisenatide GetGoal clinical trials. Diabetes Obes Metab. 2016;19:275-83.

12. Pencek R, Blickensderfer A, Li Y, et al. Exenatide twice daily: analysis of effectiveness and safety data stratified by age, sex, race, duration of diabetes, and body mass index. Postgrad Med. 2012a;124:21-32.

13. Pencek R, Blickensderfer A, Li Y, et al. Exenatide once weekly for the treatment of type 2 diabetes: effectiveness and tolerability in patient subpopulations. Int J Clin Pract. 2012b;66:1021-32.
14. Seufert J, Bailey T, Barkholt Christensen S, et al. Impact of diabetes duration on achieved reductions in glycated haemoglobin, fasting plasma glucose and body weight with liraglutide treatment for up to 28 weeks: a meta-analysis of seven phase III trials. Diabetes Obes Metab. 2016;18:721-4.

15. Home P, Miller D, Carr MC. Albiglutide provides effective glycaemic lowering across diabetes duration subgroups. Diabetologia. 2015;58:S378.

16. Usui R, Sakuramachi Y, Seino Y, et al. Retrospective analysis of liraglutide and basal insulin combination therapy in Japanese type 2 diabetes patients: The association between remaining $\beta$-cell function and the achievement of the glycated hemoglobin target 1 year after initiation. J Diabetes Investig. 2018;9:822-30.

17. Wilbrink FJ, Mudde AH, Mulder AH, Bhansing KJ. Disease duration as an indicator of the efficacy of liraglutide in patients with type 2 diabetes mellitus. J Diabetes Investig. 2018;9:979-80.

18. Fadini GP, Simioni N, Frison V, et al. Independent glucose and weight-reducing effects of Liraglutide in a real-world population of type 2 diabetic outpatients. Acta Diabetol. 2013;50:943-9.

19. Raccah D, Miossec P, Esposito V, et al. Efficacy and safety of lixisenatide in elderly ( $\geq 65$ years old) and very elderly ( $\geq 75$ years old) patients with type 2 diabetes: an analysis from the GetGoal phase III programme. Diabetes Metab Res Rev. 2015;31: 204-11.

20. Onoviran OF, Li D, Toombs Smith S, et al. Effects of glucagon-like peptide 1 receptor agonists on comorbidities in older patients with diabetes mellitus. Ther Adv Chronic Dis. 2019;10: 2040622319862691.

21. Filippatos TD, Panagiotopoulou TV, et al. Adverse effects of GLP-1 receptor agonists. Rev Diabet Stud. 2014;11:202-30. 